\title{
Graphing Calculators in the Secondary Mathematics Classroom
}

Sydney Heckes, Secondary Math Education, Research Advisor: Dr. Matt Switzer Texas Christian University

Abstract
The purpose of this project was to
research the effects of graphing
calculators in the secondary mathematics
classroom and compare my findings with
my personal experience of utilizing and
analyzing the benefits of graphing
calculators.

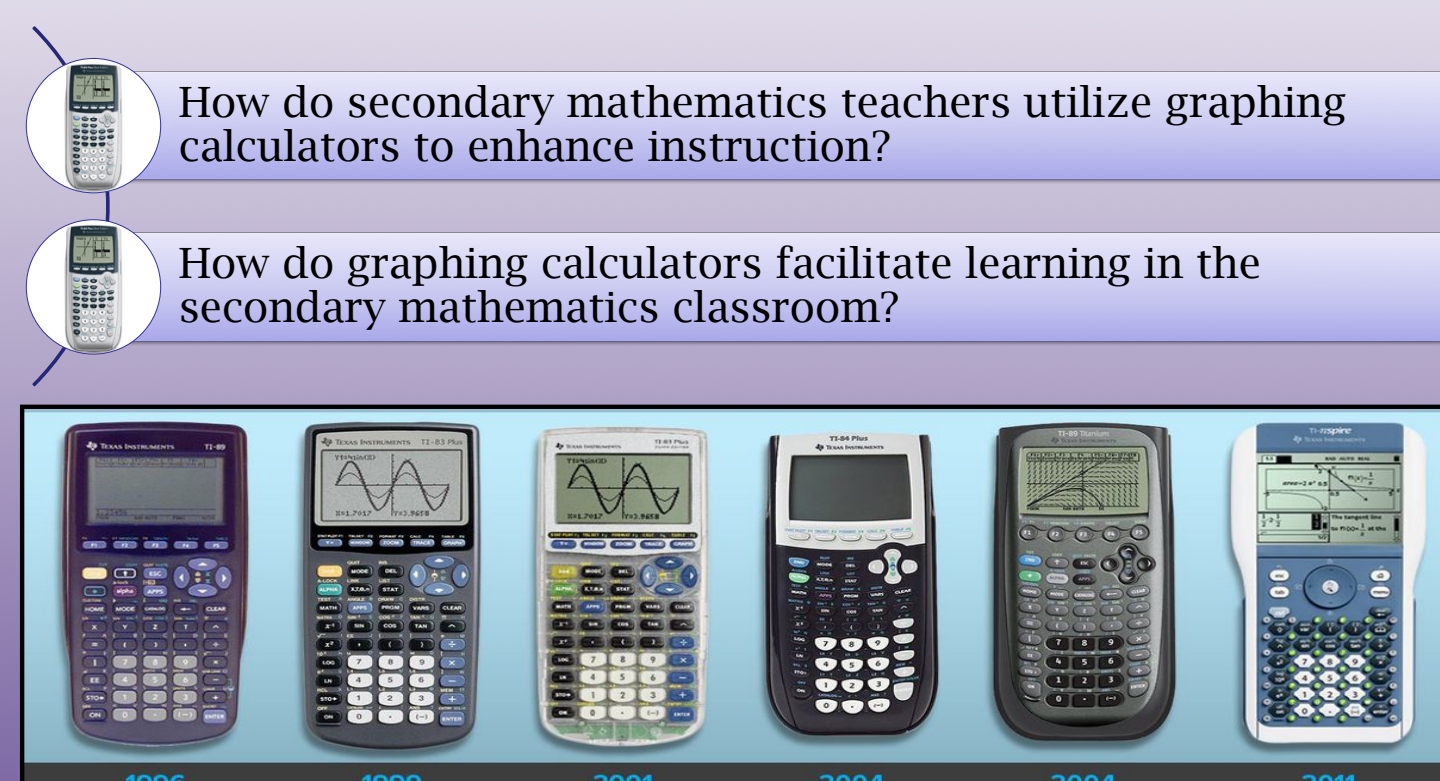

Discussion and Conclusion How do teachers utilize
enhance instruction?

Used as an aid to exhibit mathematics through multiple lenses, thereby dilfir
for diverse learning styles Used to foster a student- centered classroom that
focusses on an self-directed approach to learning calculators.

Procedures

The personal aspect of this project comes from my began Jan $3^{\text {rd }}, 2017$. I utilized graphing calculators nearly every day in
my instruction of $A P$ Calculus $A B, B C$, and Algebra Io observed the effects of graphing calculato
my classes and summarized my findings. I interviewed students in order to assess their
opinions on the benefits of learning with graphing
calculators.

I reviewed three scholarly articles to obtain
research findings on how graphing calculators are directly related to improvement in learning and

Literature Review

Pomerantz (1997) found that graphing
calculators expedite student discovery of mathematical concepts by allowing them - Pomerantz also indicated that students develop higher order thinking skills when utilizing graphing calculators. Kastberg and Leatham (2005) discussed how graphing calculators permit students to multiple representation Mason (2010) focused on how graphing calculators promote computational efficien

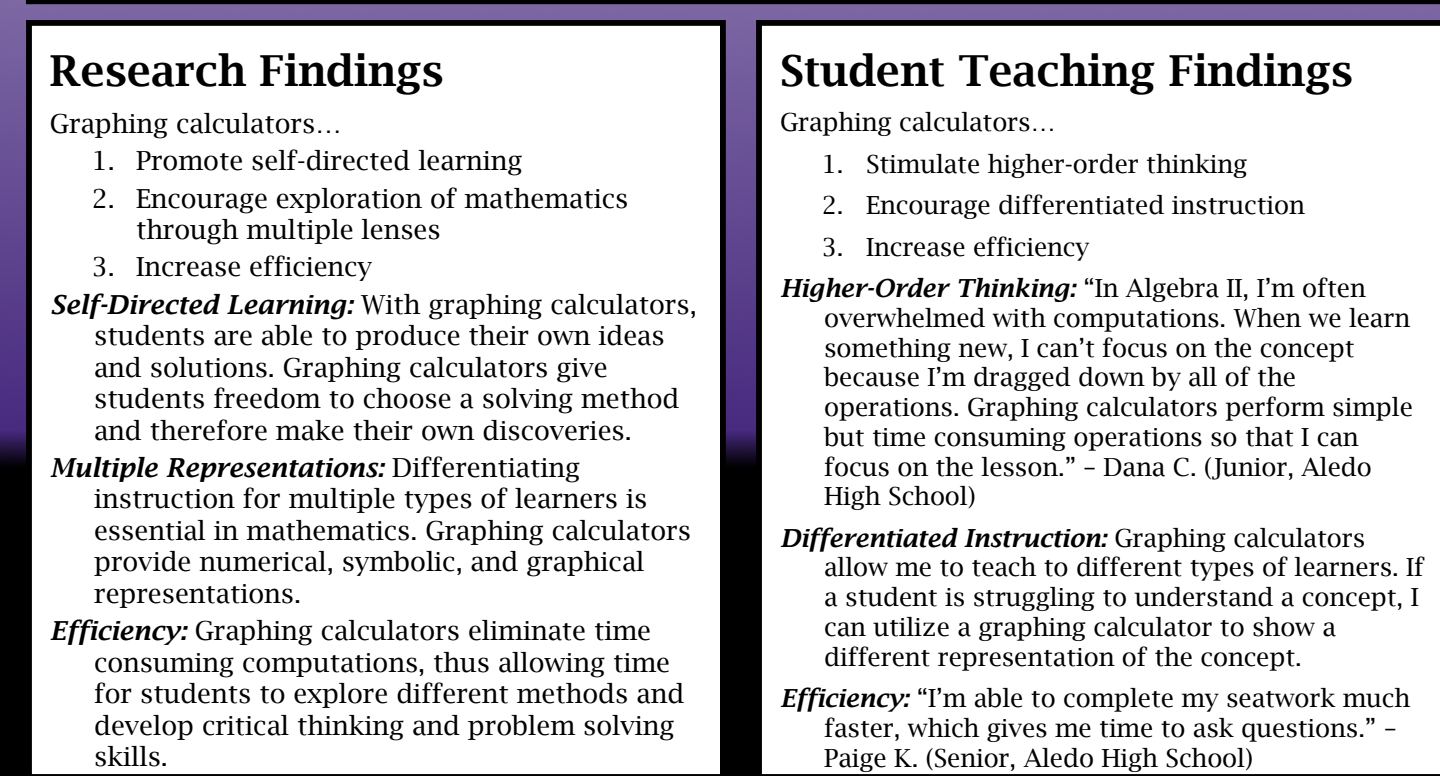
How do graphing calculators facilitate learning in the
secondary mathematics classroom? Increases efficiency, thus allowing time for
students to make sense of a concept Increases higher order thinking by providing a
simple way to check work along the way

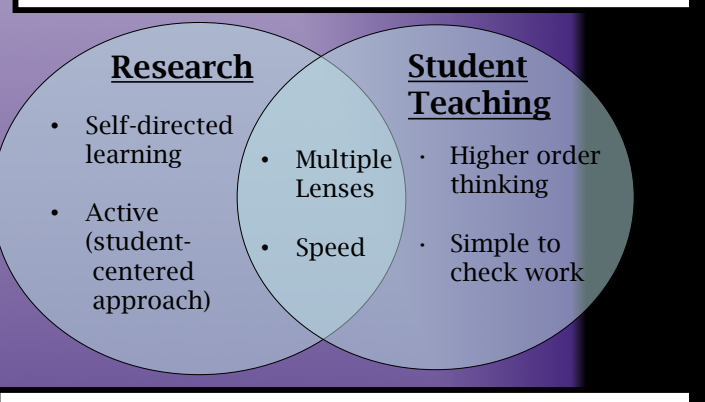

References

Kastberg, S., \& Leatham, K. (2005). Research On Graphing
Calculators at the Secondary Level: Implications for Mathematics Teacher Education. CITE Journal, 50 05 th ser. Retrieved March 15, 2017
htttp://Www citejeornal.org/Volume-5/issue-1.

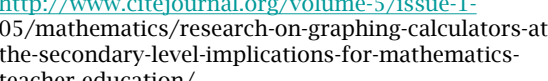
son, A. (2010, June 28). Integrating calculators in the
secondary mathematics classroom: Teachers' 'attitud

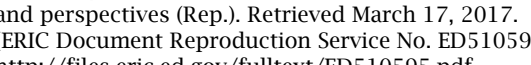
nerantz, H. (1997, December 4). The Role of Calculato
Math Education (Rep.). Retrieved March 7, 2017, fro

Contact Information 